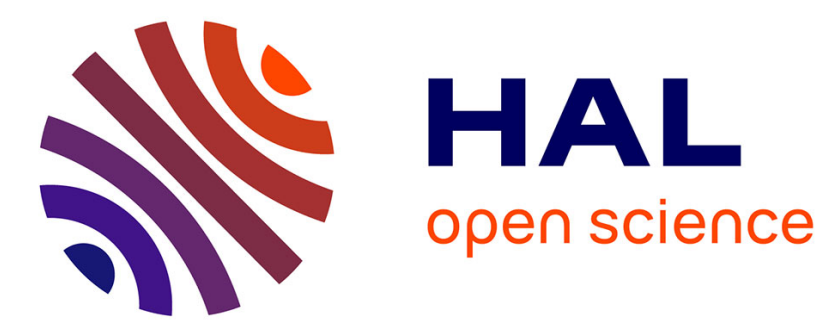

\title{
In-situ investigation of ion implantation processes by thermal wave analysis
}

\author{
H. Schlemm, H. Geiler, A. Kluge
}

\section{To cite this version:}

H. Schlemm, H. Geiler, A. Kluge. In-situ investigation of ion implantation processes by thermal wave analysis. Journal de Physique IV Proceedings, 1994, 04 (C7), pp.C7-167-C7-170. 10.1051/jp4:1994740 . jpa-00253269

\section{HAL Id: jpa-00253269 https://hal.science/jpa-00253269}

Submitted on 1 Jan 1994

HAL is a multi-disciplinary open access archive for the deposit and dissemination of scientific research documents, whether they are published or not. The documents may come from teaching and research institutions in France or abroad, or from public or private research centers.
L'archive ouverte pluridisciplinaire HAL, est destinée au dépôt et à la diffusion de documents scientifiques de niveau recherche, publiés ou non, émanant des établissements d'enseignement et de recherche français ou étrangers, des laboratoires publics ou privés. 


\title{
In-situ investigation of ion implantation processes by thermal wave analysis
}

H. Schlemm, H.D. Geiler* and A. Kluge**

FSU Jena, Inst.f. Festkörperphysik, Helmholtzweg 5, 07743 Jena, Germany

* Jenawave Engn. \& Consult., Friedrich-Schelling-Str. 11,07745 Jena, Germany

** FHG, IIS Erlangen, Artilleriestr. 12, 91052 Erlangen, Germany

\begin{abstract}
:
High-fluence $\mathrm{N}^{+}$-implantation in steel is monitored by use of nondestructive and contactless photothermal measurements during the implantation process. The modulated reflectivity is correlated with the results of Knoop hardness testing. On-line measurements on the steel surface and direct ion beam monitoring from the back side of a monitor sample are demonstrated. The maximum of the ion implantation induced hardness is strongly correlated with the phase transition indicated by the thermomodulated dielectric function.
\end{abstract}

\section{INTRODUCTION}

Photothermal techniques of modulation spectroscopy [1] and both thermal and charge carrier wave analysis [2] play a more and more important role for nondestructive and contactless evaluation of materials [3].The defined improvement of near surface properties of materials by ion implantation presumes both the exact knowledge of the effects and the control of the parameters (energy, dose, doserate, homogeneity) of the ion beam. Because of the complex processes mainly in the high dose region an in-situ control of the ion beam effect on the target is necessary. Photothermal methodes sensitively probe the thermal, electrical and structural properties of the materials. Using the sensitive and stable double modulation technique [4] to detect the thermal response in a wide range of the frequency domain beside the thermal wave analysis informations will be gained by modulation spectroscopy [1] concerning the change of the dielectric function of the material due to precipitations and internal stress.

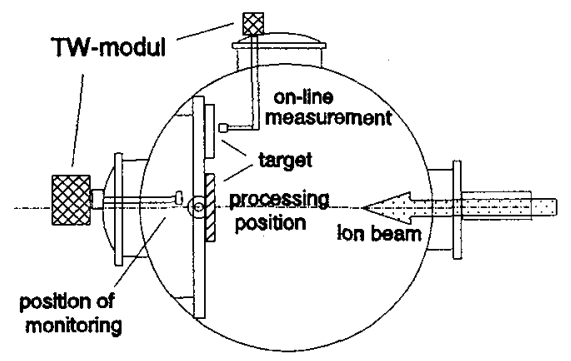

Fig.1: Scheme of the in-situ equipment mounted on the target chamber of the ion implanter 


\section{EXPERIMENTAL SETUP}

To carry out in-situ photothermal modulated reflectivity measurements the double modulation technique of a single laser beam $(\lambda=785 \mathrm{~nm})$ is applied.

One laser beam modulated with two frequencies $\Omega_{1}$ and $\Omega_{2}$ excites the sample and reads out the thermal wave by the heterodyn mixing of the backscattered field down to the differential frequency [4].

A compact equipment basing on the photothermal inspection modul "TWIN" (Jenoptik GmbH, Jena) was developed for the measurements directly in high vacuum chambers. The system is mounted on a standardized vacuum flansh, the laser beam passes a window and is focused inside the vacuum chamber by a lens (focus length $8 \mathrm{~mm}$ ) on the target. Figure 1 shows the scheme of the equipment mounted on a high current ion implanter as it is used for on-line measurement on the target outside the ion beam and for implantation monitoring directly in the beam

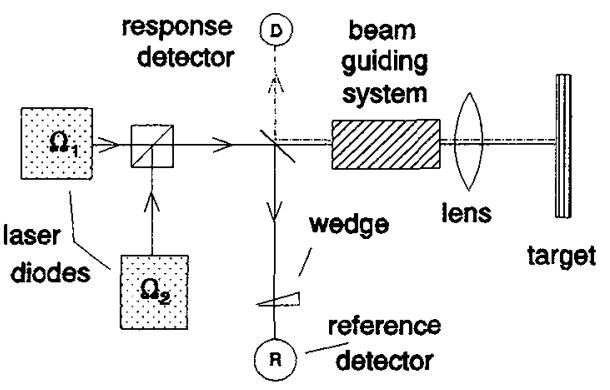

Fig.2: Optical scheme of the photothermal response module TWIN. The beam guiding system fits the laser beam into the vacuum chamber and directs it on the target. position by measuring from the back side. Instead of the Ar-laser beam applied in the first in-situ experiments [5] an optical principle (see Fig.2) including current modulated semiconductor lasers is implemented [6]. The measurement by frequency conversion in the frequency domain allows the registration of the photothermal response signal in the frequency range between $100 \mathrm{kHz}<\Omega<10 \mathrm{MHz}$ during some seconds. So processes with characteristical times of some minutes will be monitored.

\section{ON-LINE MEASUREMENT}

\subsection{Sample preparation}

All experiments were performed with circular steel discs of martensitic X90CrMoV18 (DIN 1.4112). Before ion implantation these discs were mechanically polished to decrease the surface roughness better than $0.05 \mu \mathrm{m}$. This is necessary both for reproducible Knoop hardness measurement and for the photothermal reflection investigation. No electropolishing was applied.

\subsection{Ion Implantation}

The $\mathrm{N}^{+}$-implantation was carried out by use of a high current implanter (ion energy $50 \mathrm{keV}$, ion current density $400 \mu \mathrm{A} / \mathrm{cm}^{2}$, target temperature $<120^{\circ} \mathrm{C}$ ). The target was mechanically scanned to avoid

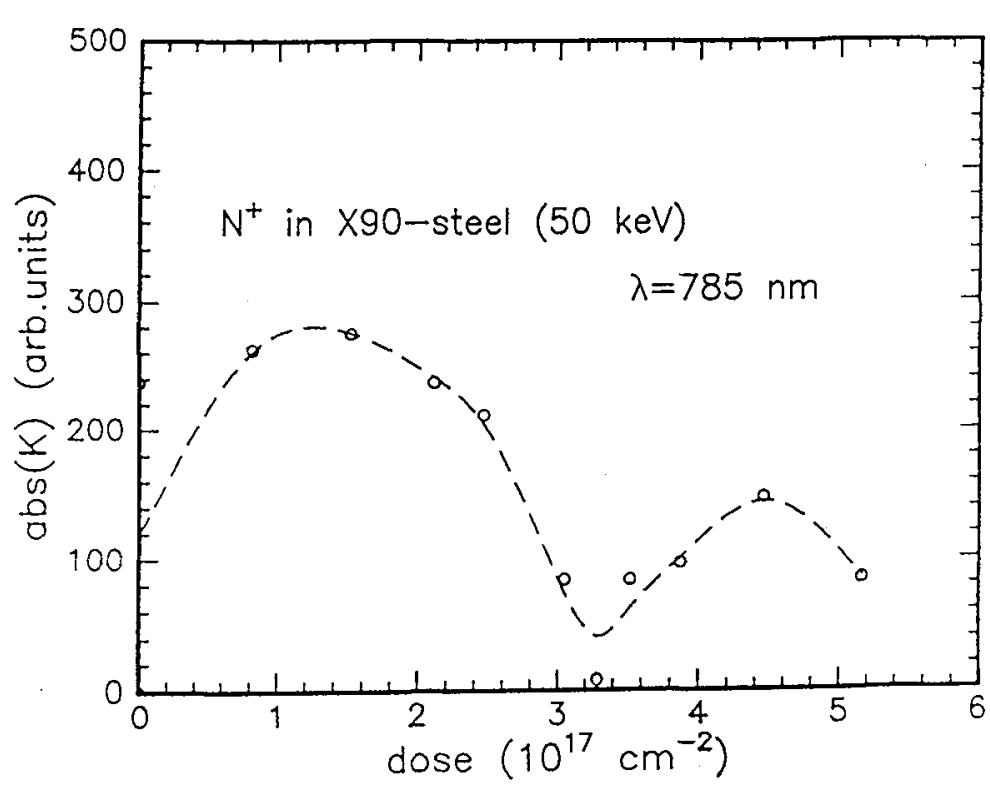

Fig.3: Amplitude of the conversion coefficient versus ion dose measured on-line during the implantation process. 
was separately controlled by a Faraday cup based current measurement including a current integrator. Periodically after 5 minutes the scan table goes to the measuring position (see Fig.1) and the photothermal response was measured versus the modulation frequency directly on the sample. In Fig. 3 the measured amplitude of the conversion coefficient at $0.2 \mathrm{MHz}$ is plotted versus the dose. The remarkable minimum (the amplitude of $\mathrm{K}$ goes through zero due to the change of the sign of the thermomodulation factor) is correlated with the maximum of the microhardness of the implanted layer [7]. The measured conversion coefficient $K(\Omega)$ represents the complex thermal wave function $\hat{\mathrm{t}}_{\lambda}$ normalized by the exitation power per spot radius $\mathrm{P} / \mathrm{w}$ and integrated over the lateral space frequencies $\lambda$ combined with the thermomodulation factor $\mathrm{dR} / \mathrm{dT}$ :

$$
K(\Omega)=\frac{1}{R} \frac{\partial R}{\partial T} \int_{0}^{\infty} \lambda d \lambda \hat{t}_{\lambda}(\Omega) e^{-\frac{\lambda^{2}}{4}}
$$

The integration over the space frequencies $\lambda$ is necessary due to the convolution of the radial distribution of the thermal wave with the Gaussian intensity profile of the laser beam.

The integral can be separated by its $\Omega$ dependence and describes the thermal properties meanwhile the thermomodulation factor represents the spectroscopic features of the material. This analysis is applied to control the change of the tribological properties of steel surfaces by high dose implantation of $\mathrm{N}^{+}$[7].
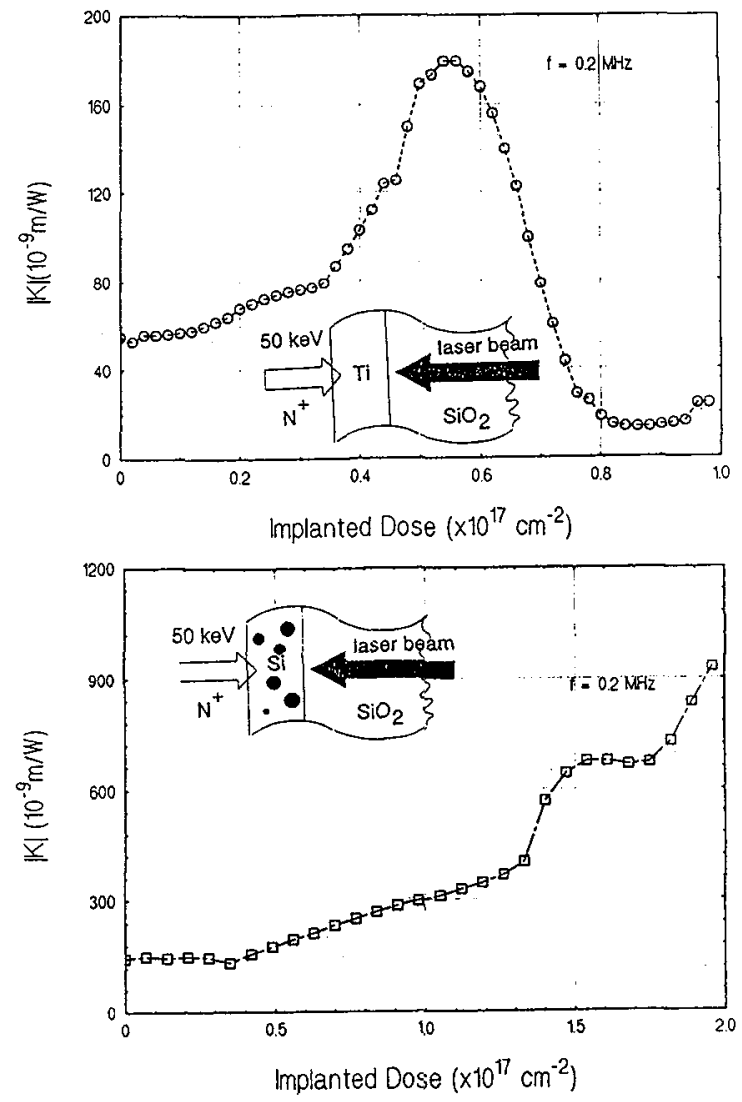

Fig.4: Amplitude of the conversion coefficient during $\mathrm{N}^{+}$-implantation in (a) $\mathrm{Ti}$ layer on glass and (b) glass versus ion dose

\section{ION BEAM MONITORING}

\subsection{Preparation of monitor layers}

To measure directly the response under ion irradiation the method of back side excitation [5] of a monitor layer is used. Two types of layers were prepared: (a) Titanium evaporated on glass and (b) microscopic Silicon precipitates in glass. The thickness of both layers is about $200 \mathrm{~nm}$. In the case of a $50 \mathrm{keV} \mathrm{N}^{+}$-implantation a thickness of about $150 \mathrm{~nm}$ is influenced so the whole implantation induced changes of the structure should be restricted on the monitor layer.

\subsection{Implantation monitoring}

If the front side of the monitor layer is subjected to the $\mathrm{N}^{+}$ion irradiation the change of the photothermal response signal can be registrated. The conversion coefficient is recorded versus implantation time so the dose can be measured by calibration. Fig.4 shows the results for the 
implantation in the two types of the monitor layer. Note the different regions of monotonous growing signals for both layer systems. This gives the possibility to monitor the dose range from $10^{16} \mathrm{~cm}^{-2}$ up to $5 \times 10^{16} \mathrm{~cm}^{-2}$ applying the Ti/glass system and above $5 \times 10^{16} \mathrm{~cm}^{-2}$ up to $2 \times 10^{17} \mathrm{~cm}^{-2}$ by use of the precipitate-glass system.

Each system represents a nearly linear interval of the response dependence on dose and more or less oscillating parts, which are due to phase changes (formation of TiN and $\operatorname{Si}_{\mathrm{x}} \mathrm{N}_{\mathrm{y}}$, respectively) in the high dose region. This changes the optical thickness of the layer and the thermomodulation factor [1].

\section{CONCLUSIONS}

The results presented in the paper demonstrate the capability of photothermal on-line measurement and monitoring for in-situ control of ion implantation processes in the dose range between $10^{16} \mathrm{~cm}^{-2}$ up tp $5 \times 10^{17} \mathrm{~cm}^{-2}$. Nonelectrical measurements in this high dose range are very important because of the considerable fraction of neutrals (nearly 90\%) in the ion beam of high current implanters.

\section{ACKNOWLEDGEMENT}

The authors thank Dr. Dietz (BMFT Germany) and the Jenoptik GmbH for the support.

\section{references:}

[1] B.Batz, in "Semiconductors and Semimetals " Vol.9 ,ed. by R.K.Willardson and A.C.Beer, Academic Press 1972, p.315

[2] A.Rosencwaig in "Photoacoustic and Thermal Wave Phenomena in Semiconductors", ed. by A.Mandelis, Elsevier, New York 1987, p.98

[3] G.Busse, H.G.Walther, in "Principles and Perspectives of Photothermal and Photoacoustic Phenomena", ed by A.Mandelis, Elsevier New York 1992, p.205

[4] M.Wagner, H.D.Geiler ; Meas.Sci.Technol. 22(1991)1088

[5] H.D.Geiler, N.Winkler, D.Schiller; in "Photoacoustic and Photothermal Phenomena III", ed. by D.Bicanic, Springer Series in Optical Sci. Vol.69, Springer, Berlin 1992,p.688

[6] H.D.Geiler, M.Wagner,P.Kowalski, R.Bleiß; in "Photoacoustic and Photothermal Phenomena III", ed. by D.Bicanic, Springer Series in Optical Sci. Vol.69, Springer, Berlin 1992,p.477

[7] H.D.Geiler, H.Karge, A.Kluge; Proc.int.Conf.SIMMB'93, Kanazawa, Japan, 13.-17-9-1994, p.92 